\title{
P02.17. Building a database of validated pediatric outcomes: an investigation of compliance with established reporting standards
}

\author{
D Adams ${ }^{1 *}$, Y Liu' ${ }^{1}$, S Surette ${ }^{1}$, L Hartling $^{2}$, S Vohra $^{1}$ \\ From International Research Congress on Integrative Medicine and Health 2012 \\ Portland, Oregon, USA. 15-18 May 2012
}

\section{Purpose}

Many pediatric trials are published annually, but criticism exists regarding outcome measures used and their reporting. Reporting standards set out by the Consolidated Standards of Reporting Trials (CONSORT) group require accurately defined outcomes, and apply equally to studies of conventional or complementary and alternative medicine (CAM). The objective of this study was to conduct a systematic review to identify gaps in outcome reporting in pediatric randomized controlled trials (RCTs).

\section{Methods}

Ten journals with the highest impact factors were searched for pediatric RCTs published between 20002010. Two independent reviewers conducted screening and data extraction on $20 \%$ of randomly selected included studies. Variables extracted included: journal, sample size, participant age, condition under study, intervention, control, and details of primary outcome and outcome measurement tools.

\section{Results}

Searches identified 2229 unique references. Screening of a random sample of $2.5 \%$ determined that most (97\%) were RCTs, thus full text for all references were obtained. Inclusion screening was carried out simultaneously with data extraction. Of the 446 articles screened to date, $66 \%$ were included. Participant age ranged from 20 weeks gestation to 20 years. Most (65\%) were of treatment rather than prevention. Commonly used controls included placebo (35\%) and another intervention (33\%).
With respect to primary outcome reporting, 34\% of trials did not identify a primary outcome. Half (53\%) reported at least one primary outcome; of these, $55 \%$ described one outcome as primary and $38 \%$ identified more than one outcome as primary. One quarter of the trials that included only one primary outcome used a questionnaire or scale-based tool and of these, only $26 \%$ presented information on tool clinometrics.

\section{Conclusion}

This project will help identify gaps in the quality of outcome reporting in pediatric trials published in top journals over the past 10 years, leading to recommendations for improvements in reporting standards.

\section{Author details \\ 'University of Alberta, Edmonton, Canada. ${ }^{2} \mathrm{ARCHE}$, Dept of Pediatrics, University of Alberta, Edmonton, Canada.}

Published: 12 June 2012

doi:10.1186/1472-6882-12-S1-P73

Cite this article as: Adams et al:: P02.17. Building a database of validated pediatric outcomes: an investigation of compliance with established reporting standards. BMC Complementary and Alternative Medicine 2012 12(Suppl 1):P73.

${ }^{1}$ University of Alberta, Edmonton, Canada

Full list of author information is available at the end of the article

(c) 2012 Adams et al; licensee BioMed Central Ltd. This is an Open Access article distributed under the terms of the Creative Commons 